\title{
Modelling concepts of passive arch action in undercut slopes
}

\author{
T Pipatpongsa Kyoto University, Japan \\ MH Khosravi University of Tehran, Iran \\ J Takemura Tokyo Institute of Technology, Japan \\ C Leelasukseree Chiang Mai University, Thailand \\ P Doncommul Electricity Generating Authority of Thailand, Thailand
}

\begin{abstract}
The classical textbook "Rock Slope Engineering" by Hoek and Bray (1977, p. 166) states that, "It is not usual for the toe of a slope to be undercut ...". Therefore, it is of great importance to evaluate the maximum undercut width. This is because undercutting at the toe of a slope is considered as a destabilising mechanism. For a problem limiting an undercut slope lying on a bedding plane, a practical technique for surface mining was established at the Mae Moh mine located in Northern Thailand under collaborative research with the Electricity Generating Authority of Thailand. This research successfully resulted in a fundamental study on the failure mechanism of undercut slopes (Pipatpongsa et al. 2009-2013; Khosravi et al. 2009-2012, 2016). The possible modes of slope failure, due to an excavation at the toe of a slope, were examined through a series of simple physical model tests using humid sand placed on an inclined rigid plate. While ensuring the removal of propped portions of sand at the toe of the slope did not cause the collapse of the sand mass, due to arch action over the abutments. However, the effect of the arch action could not be maintained once the excessive removal of propped portions had been made. Different failure modes were observed in accordance with various boundary/material conditions. The arch action and its mechanism of load transfer were confirmed through a number of physical and numerical models. The failure mechanism along the inclined plane of weakness was seen to involve the passive condition, whereby the major principal stresses dominate the force supporting the arches in the circumferential direction, and the minor principal stresses represent the force confining the stacks of arches. This paper summarises the concepts used in setting up $1 \mathrm{~g}$ physical models, the required equipment and the measurement techniques. The development of the physical models in the preliminary study, the $1 \mathrm{~g}$ physical modelling and the geotechnical centrifuge modelling conducted from 2010-2015 are also reviewed. Based on the results of field tests, the new design concept for undercut slopes proposed in the previous study (Pipatpongsa et al. 2013) is correctly revised in this paper.
\end{abstract}

\section{Introduction}

Undercutting at the toe of a slope is considered as a destabilising mechanism in rock slope engineering. The classical textbook written by Hoek and Bray $(1977$, p. 166) states that "It is not usual for the toe of a slope to be undercut, either intentionally by mining or by natural agencies such as the weathering of underlying strata or, in the case of sea cliffs, by the action of waves". They also derived a general solution for planar failure considering the fact that the primary failure mode involves the sliding of the rock along a failure plane with a vertical tension crack. A more recent version of this book (Wyllie \& Mah 2004, p. 366) summarises slope design concepts consisting of the basic slope types and specific slope design criteria. A preliminary design criterion under "the slope design concept F-II, where the bedding dips shallowly to moderately out of the slope", suggests that mine planners should "excavate the slope parallel to the bedding and not undercut the bedding where the bedding joints are continuous or the bedding dip is steeper than the friction angle, but not excavate it steeply enough to initiate buckling, ploughing, bilinear or other slab-type failures" because the planar failure on the bedding can be initiated by some undercutting 
of the toe of the slope. The conventional approach does not provide flexible design concepts when the toe of a slope, in which sliding can occur on a bedding plane, is undercut in three-dimensional (3D).

Alternative slope design concepts were required at the Mae Moh mine in Northern Thailand. Pipatpongsa et al. (2009) reported an engineering challenge in Area 4 and Area 4.1 where a portion of lignite at seams $Q$ and $\mathrm{K}$, with a length 300-350 m, had been left to support an unstable rock mass, with a height of 80-120 m, resting on clay-filled bedding planes with dip angle $\alpha=12^{\circ}-15^{\circ}$. As shown in Figure 1 , clay seams G1 and G2, with drained cohesion $c^{\prime}=0 \mathrm{kPa}$ and drained friction angle $\phi^{\prime}=13^{\circ}-15^{\circ}$, can bring about the plane failure sliding into the pit if the toe of the slope acting as the counterweight balance is excavated. According to stability analyses under a planar slope failure criterion, using $\alpha=15^{\circ}$ and $\phi^{\prime}=14^{\circ}$, the Factor of Safety could be as low as $F S=\tan \left(\phi^{\prime}\right) / \tan (\alpha)=0.93$. As $F S<1$, an unstable rock mass would slip along the clay seams and cause a massive ground slippage of up to 1.75 million $\mathrm{m}^{3}$ plunging into the pit once $\mathrm{G} 1$ was daylighted. Moreover, the groundwater above G1 would rise drastically in the rainy season and cause an unavoidable reduction in the shearing resistance on the bedding plane. The decision as to which alternative mining technique to adopt was based on cost and operational convenience in comparison to the technique involving the removal of the unstable rock mass.

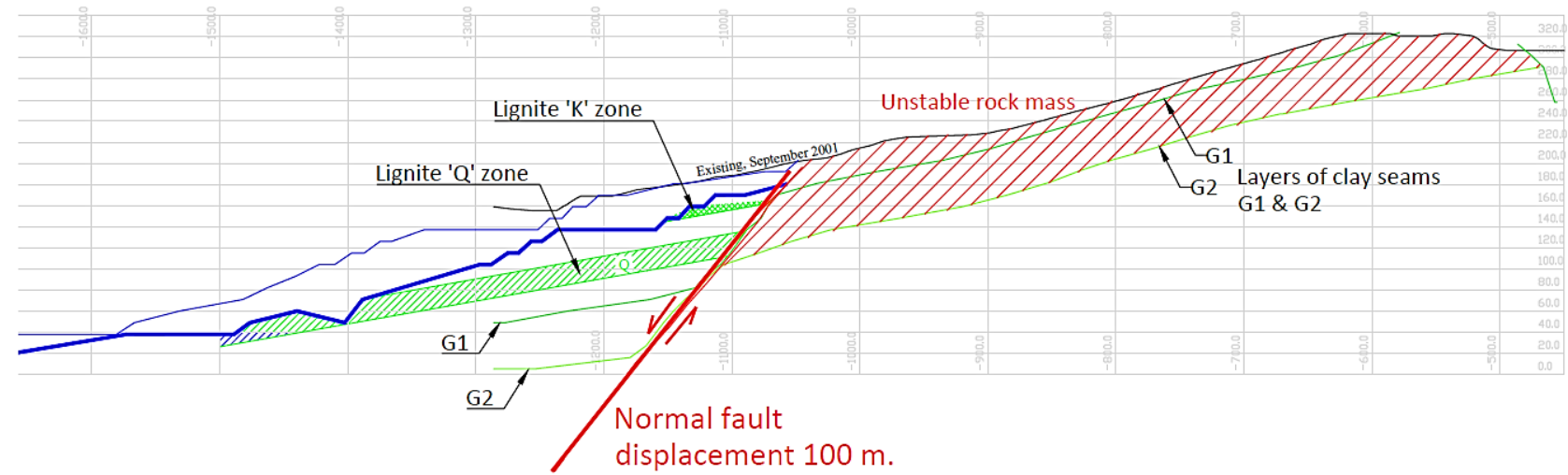

Figure 1 Cross-section NE-4 in Area 4 where a portion of lignite seams $\mathrm{K}$ and $\mathrm{Q}$ had been left to counterweight the unstable rock mass resting on clay seams $\mathrm{G} 1$ and $\mathrm{G} 2$

According to Khosravi et al. (2010), an excavation in Area 4.1 would take up to 370 days during a rainy season, provided that two huge shovels with the loading capacity of 120 thousands $\mathrm{m}^{3} / \mathrm{month}$ were employed to continuously remove the unstable rock mass with a volume of approximately $3 \times 10^{6} \mathrm{~m}^{3}$ from this area. Otherwise, this slope could be reinforced by mortar shear pins, with a diameter of $0.152 \mathrm{~m}$ and shear strength of $18 \mathrm{MPa}$. If so, almost 4,000 shear pins would be required to raise the Factor of Safety to one. Considering the condition at the mine site, the installation of such a large number of shear pins would not be an easy task. Furthermore, the cost of this reinforcement would be so high, as to make it economically unpractical. Neither the removal of the unstable rock mass in Area 4.1 nor reinforcement by shear pins was found to be economically reasonable; thus, a different approach needed to be found.

It has been realised that lateral load transfer mechanisms, using sequences of cut and fill, would be a key concept for revising excavation plans. As illustrated in Figure 2, instead of wholly excavating the toe of the slope, some parts of it are excavated, but the main parts are left as abutments to prevent the unstable slope from sliding downward. During the excavation of lignite from one side, rock mass waste can be dumped in-pit at the opposite side. As the height of the excavated portion is $80-100 \mathrm{~m}$, a stepped excavation is considered by determining the height and the width of the benches. Portions of lignite and rock can partially support the inclined driving load from the unstable rock mass by arch action (Pipatpongsa et al. 2010); the conceptual idea is shown in Figure 3. Soil arching is a result of elastic behaviour in which stresses are redistributed from yielding to less-yielding parts or from weak to stiffer parts (Terzaghi 1936). Moreover, frictional side supports, confining the vertical planes of the unstable rock mass, can aid in resisting the full loading of the inclined rock mass. 


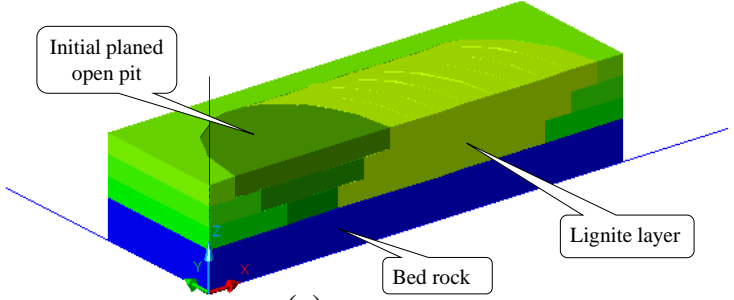

(a)
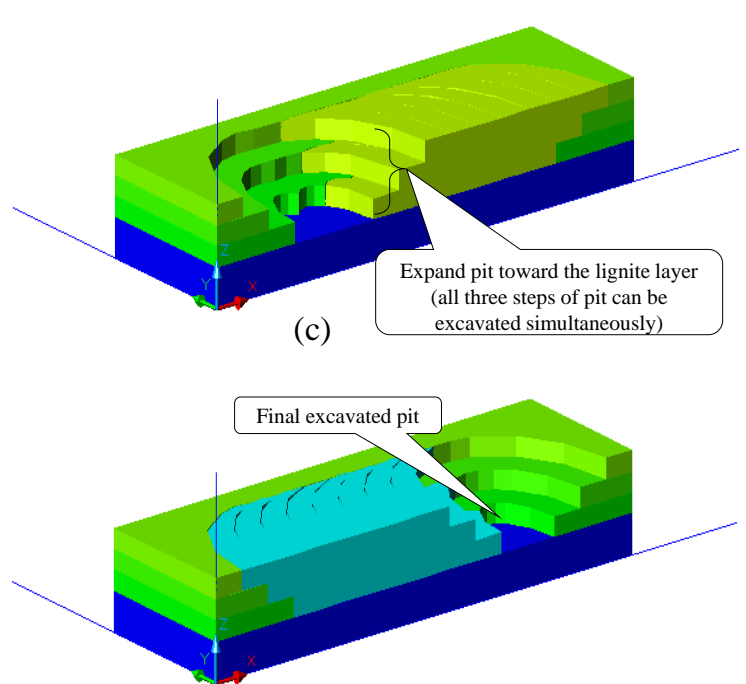

(e)

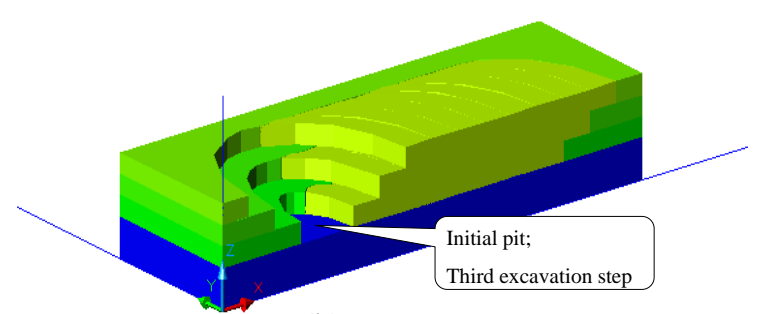

(b)
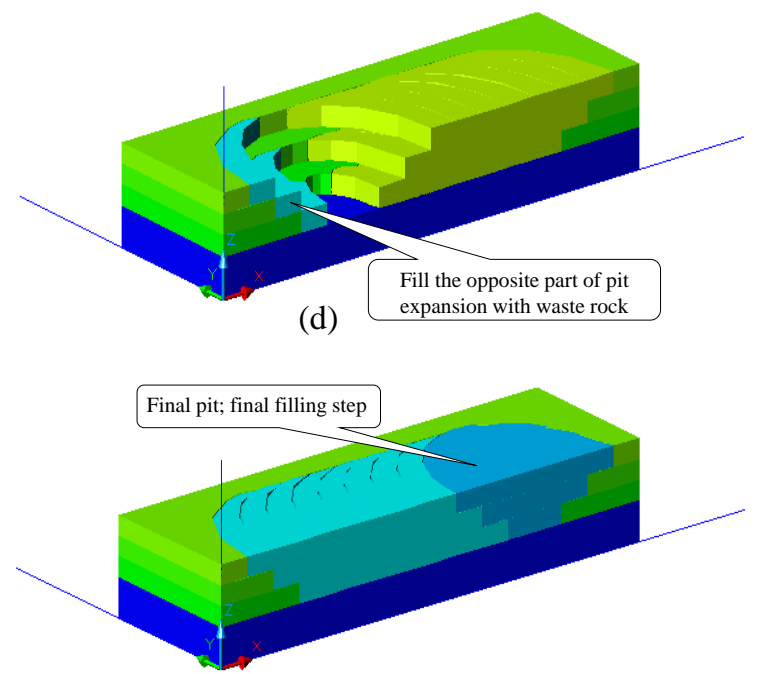

(f)

Figure 2 Schematisation of moving-pit excavation portraying cut-and-fill sequences from step (a) to (f) (modified from Pipatpongsa et al. 2009; Khosravi et al. 2010)

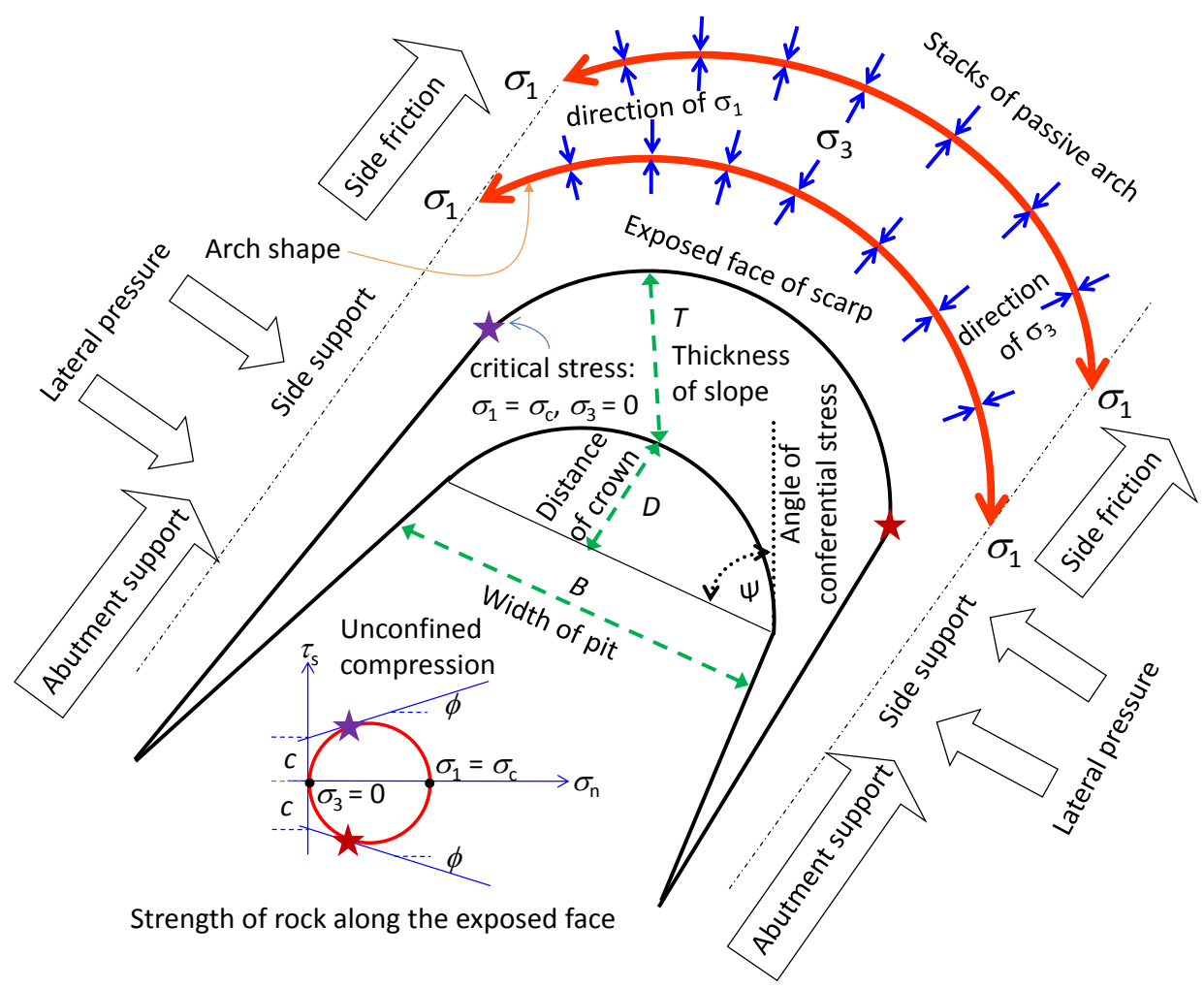

Figure 3 Schematisation of load transfer mechanism in the initial pit under passive arch action slanting in the direction of gravity in a slope confined by side supports and propped by abutments at the toe (modified from Pipatpongsa et al. 2010) 
Feasible studies on the proposed method have been conducted with physical models to understand the mechanisms of failure. The worked-out theory had been developed and translated into practice during 2010-2015. The updated knowledge was based on physical modelling, the geotechnical centrifuge modelling and the numerical modelling. This paper reviews the main concepts, the required equipment and the measurement techniques employed in experiments. Finally, the new design concept for undercut slopes and the interpretation of the field test results are discussed in this paper.

\section{Methodology}

Through a series of simple physical model tests using humid sand placed on an inclined rigid plate, the possible modes of slope failure due to the excavation at the toe of the slope were examined. Preliminary sets of physical model tests had been conducted to ensure that the removal of propped portions of sand at the toe of the slope did not cause the collapse of the sand mass due to arch action over the abutments. However, the effect of this arch action cannot be maintained once the removal of an excessive amount of propped portions has been made.

\subsection{Preliminary physical model}

Through a series of simple physical models, Khosravi et al. (2009) investigated the load transfer mechanism and failure of a slope sitting on an oblique plane with the propping portion along its toe, as illustrated in Figure 4. Humid silica sand No. 6 was uniformly layered inside a rigid wooden frame fixed on the slope and the base, which were made of rigid wooden plates covered by a vinyl plastic sheet. The testing conditions were varied, namely, the width of the slope and the sand density with and without side supports, and surcharges were applied at the top. As the slope was sliced and cut in sequence by a hand scoop, starting from the middle, the removal of the propping portions caused a slip along the oblique plane. A number of failure modes, observed in the inclined slope, were found to be related to the boundary and loading conditions, as shown in Figures 5-10 (modified from Khosravi et al. 2009). In summary, the observed failure mechanisms depended on the degree of sand compaction (strength of the material), height of the slope (surcharge), and lateral stiffness (side supports).

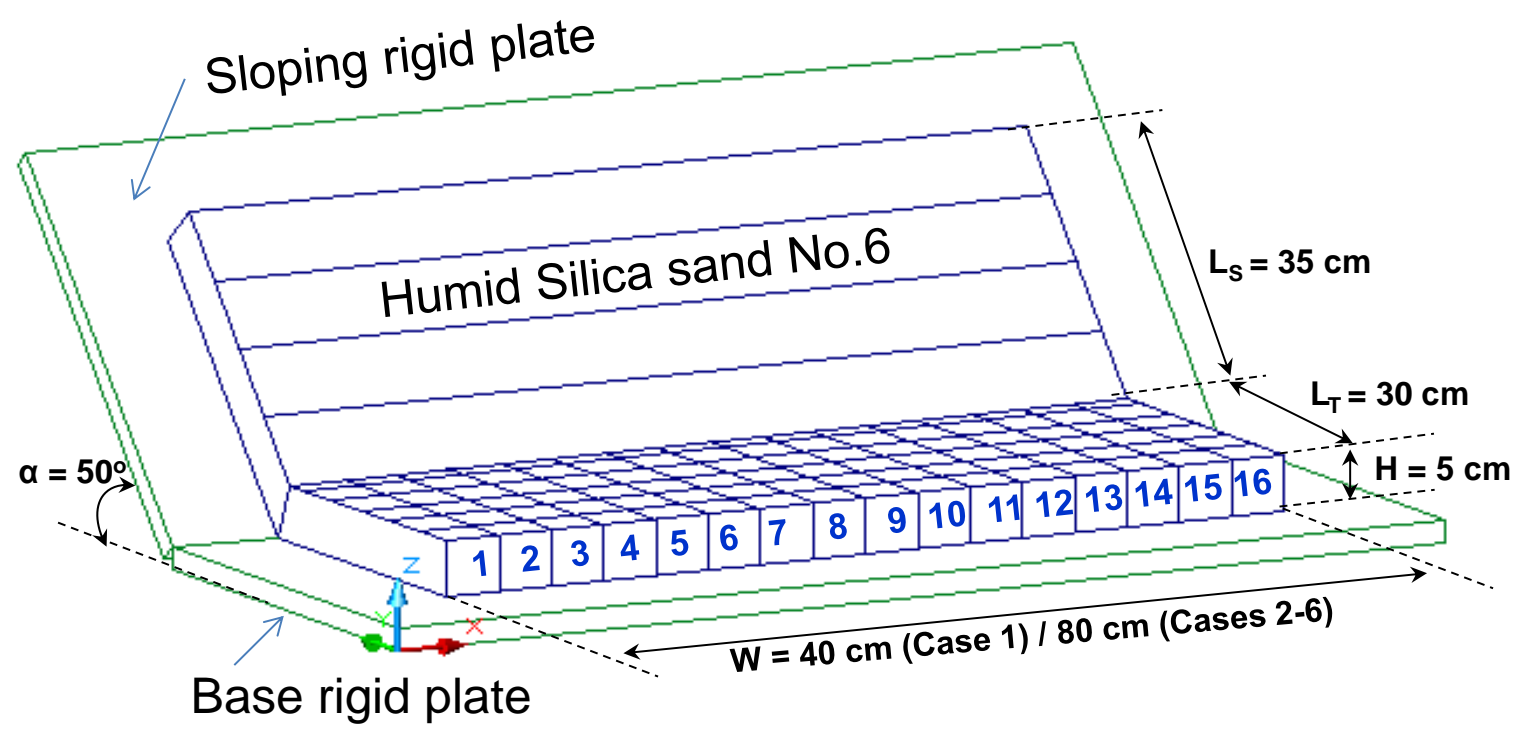

Figure 4 Outline of the preliminary undercut slope model made of humid silica sand No. 6 placed on oblique and horizontal wooden plates (after Khosravi et al. 2009) 


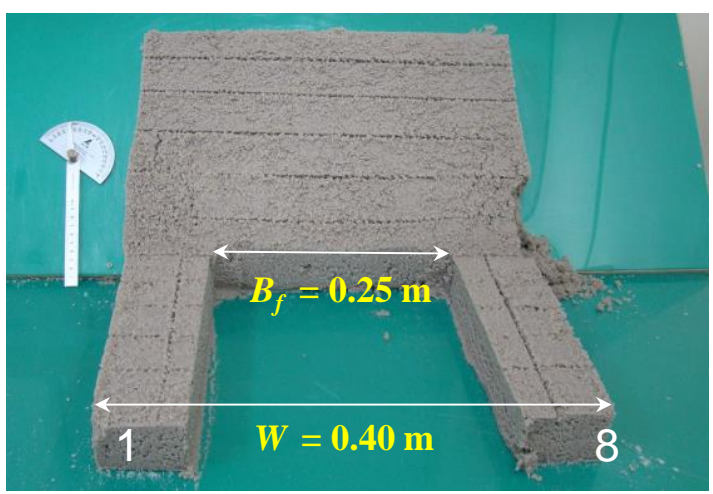

Figure 5 Pillar spalling after undercutting a loosely compacted short-span slope with neither surcharge nor side supports

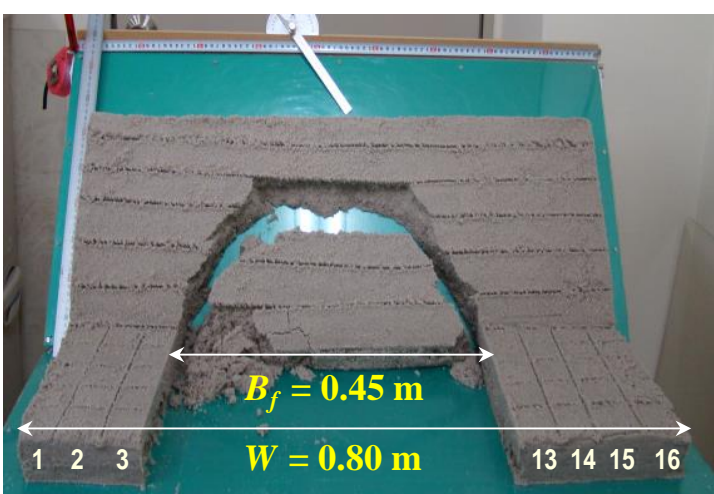

Figure 7 Arch collapse after undercutting a moderately compacted long-span slope with neither surcharge nor side supports

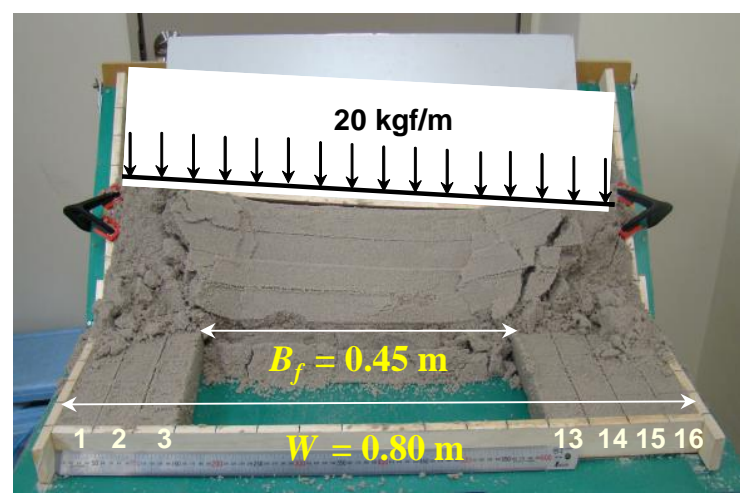

Figure 9 Abutment buckling after undercutting a moderately compacted long-span slope with continuously uniform surcharge and side supports

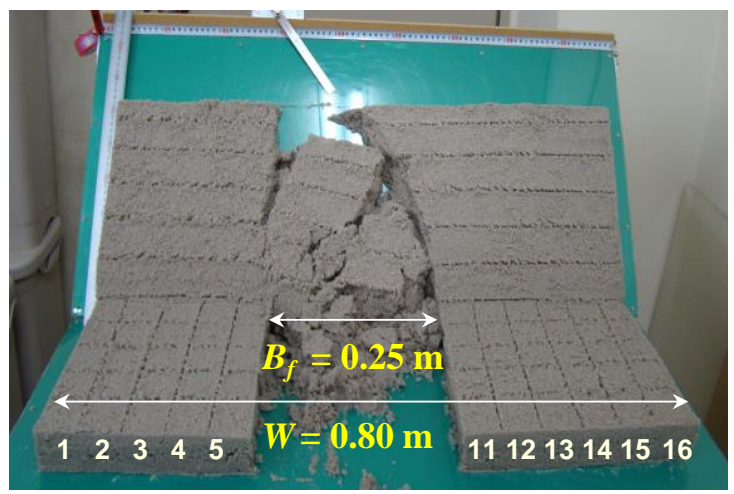

Figure 6 Slope avalanche after undercutting a loosely compacted long-span slope with neither surcharge nor side supports

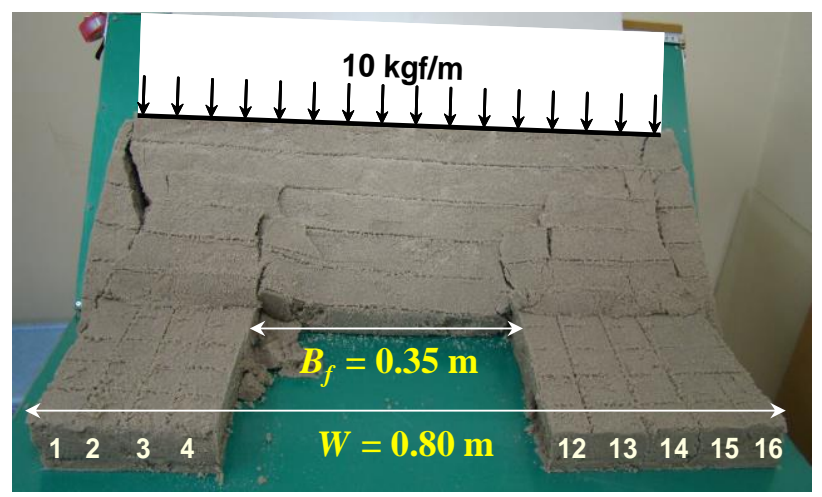

Figure 8 Abutment collapse after undercutting a moderately compacted long-span slope with continuously uniform surcharge and no side supports

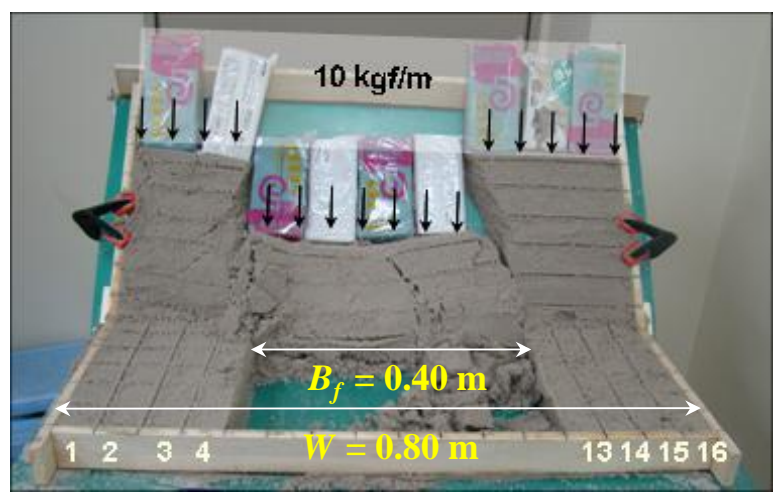

Figure 10 Punching block after undercutting a moderately compacted long-span slope with disintegrable uniform surcharge and side supports

Since the actual slope at the site is wide, the short-span model shown in Figure 5 would not be realistic. A geological report has revealed that the rock mass in Area 4.1 is not considerably fractured, therefore the slope avalanche would not be occurred like in Figure 6, but might be prone to the arch collapse shown in Figure 7 for local portions. If the side constraints are not sufficiently stiff, the abutments could unravel, as shown in Figure 8. Since Area 4.1 is part of a wider slope, Figures 9 and 10 are thought to be potential cases that are confined by lateral boundaries and loaded by overburden pressure. In order to investigate the effects of lateral boundaries, slope models with and without side supports were studied. The size of the 
model needs to be enlarged in order to provide enough space for miniature pressure gauges and their cables. The installation of a camera above the model is also required for image processing using the particle image velocimetry technique (White et al. 2003).

\subsection{Instrumented $1 \mathrm{~g}$ physical model}

The preliminary physical model tests provide an idea for building the slope model structure that was modified from a table for which the base had a length of $1.50 \mathrm{~m}$ and a width $1.00 \mathrm{~m}$. Aluminium plates with a thickness of $10 \mathrm{~mm}$ were used to support the $1.30 \mathrm{~m}$ wide slope model with a $0.80 \mathrm{~m}$ long slope. As the slope and the base are joined together by $10 \mathrm{~mm}$ thick acrylic plates, the angle of the slope can be adjusted later to any angle. The side-supporting frames were made of pieces of $10 \mathrm{~mm}$ thick acrylic plates that can be adjusted to create a slope up to $0.1 \mathrm{~m}$ in thickness. A strut in front of the model was mounted onto the structural frame in order to fix a digital camera (Sony Cyber-short DSC-H50) with an automatic shutter. The location of the holder and the orientation of the camera should be adjustable so that photos can be taken of the slope appearing in the centre in a normal direction. Figure 11 shows an outline of the slope and the base model marking the locations for the pressure gauges (P306S-01), the shear gauges (S10-005) and the potentiometer (MLT-38000201). An adjustment for uniform lighting is also necessary in order to avoid shadows and reflections.

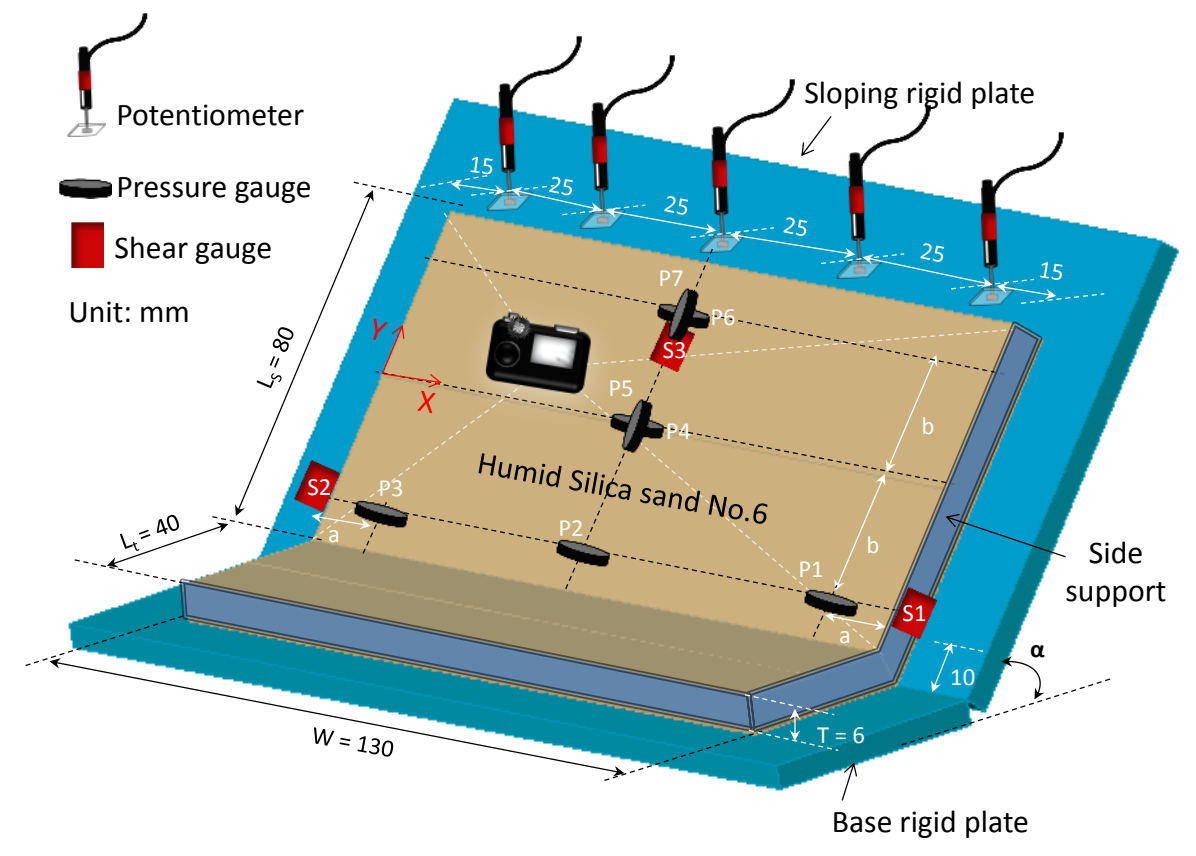

Figure 11 Outline of the slope and the base model with the locations of the instruments, namely, the potentiometer, the pressure gauges and the shear gauges (after Khosravi et al. 2011a)

The purpose of the physical model is to observe the behaviours of typical undercut slopes before failure, at failure and after failure, rather than to model the actual site. Therefore, the geometric similitude is not restricted in the model tests. Despite there being many choices of materials, silica sand No. 6 , used for the preliminary physical model, was chosen because its uniform gradation with average particle diameter $D_{50}=0.33 \mathrm{~mm}$, uniformity coefficient $C_{u}=1.42$, curvature coefficient $C_{c}=1.03$, specific gravity $G_{s}=2.65$, maximum void ratio $e_{\max }=1.132$, minimum void ratio $e_{\min }=0.711$ and internal friction angle $\phi=41.5^{\circ}$ are good enough for manual compaction. It is understood that the material at the site is claystone, not cohesionless sand. Moreover, passive arching requires a certain degree of cohesion; therefore, a certain amount of suction is required. It has been found that compaction with a $10 \%$ water content can achieve the apparent cohesion of $c=8 \mathrm{kPa}$, which is sufficient for the undercut slope model to fail within the limited width of $1.30 \mathrm{~m}$. If the water content is too high, water bleeding will occur after the slope models have been prepared. A specific compaction at relative density $D_{r}=10-12 \%$ was chosen to suppress dilatancy 
because highly compacted sand exhibits high dilatancy when being sheared. If sand with finer particles is employed, the undercut slope model might not fail within the size limit; therefore, suitable material is found by trial and error. Properties of silica sand No. 6 and its interface resistance are reported in Khosravi et al. (2013).

Humid silica sand No. 6, with a total density of $13.7-14.0 \mathrm{kN} / \mathrm{m}^{3}$ and a water content of $10 \%$, was considered to be suitable material for use in the $1 \mathrm{~g}$ physical model of the undercut slope. Figure 12 reveals the typical procedure of the slope preparation in steps (a)-(c) and the typical undercutting process in steps (d)-(f). For this test, the $0.06 \mathrm{~m}$ thick, $1.30 \mathrm{~m}$ wide and $0.80 \mathrm{~m}$ long slope inclined at $30^{\circ}$ to the horizontal plane was prepared. The slope failed at an undercut width of $0.7 \mathrm{~m}$ with a shear plane developed at one corner of the detached portion of the slope. Detailed explanations about the experiments could be found in Khosravi et al. (2011a).
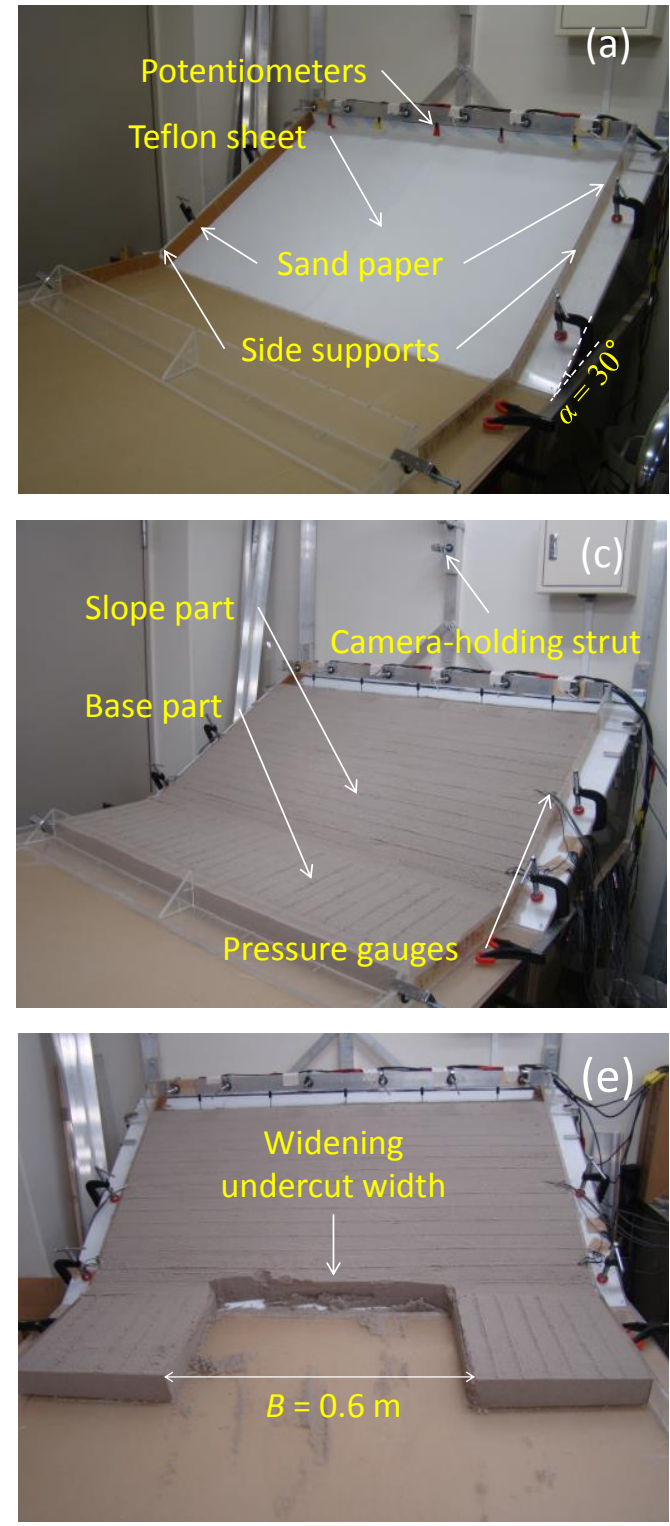
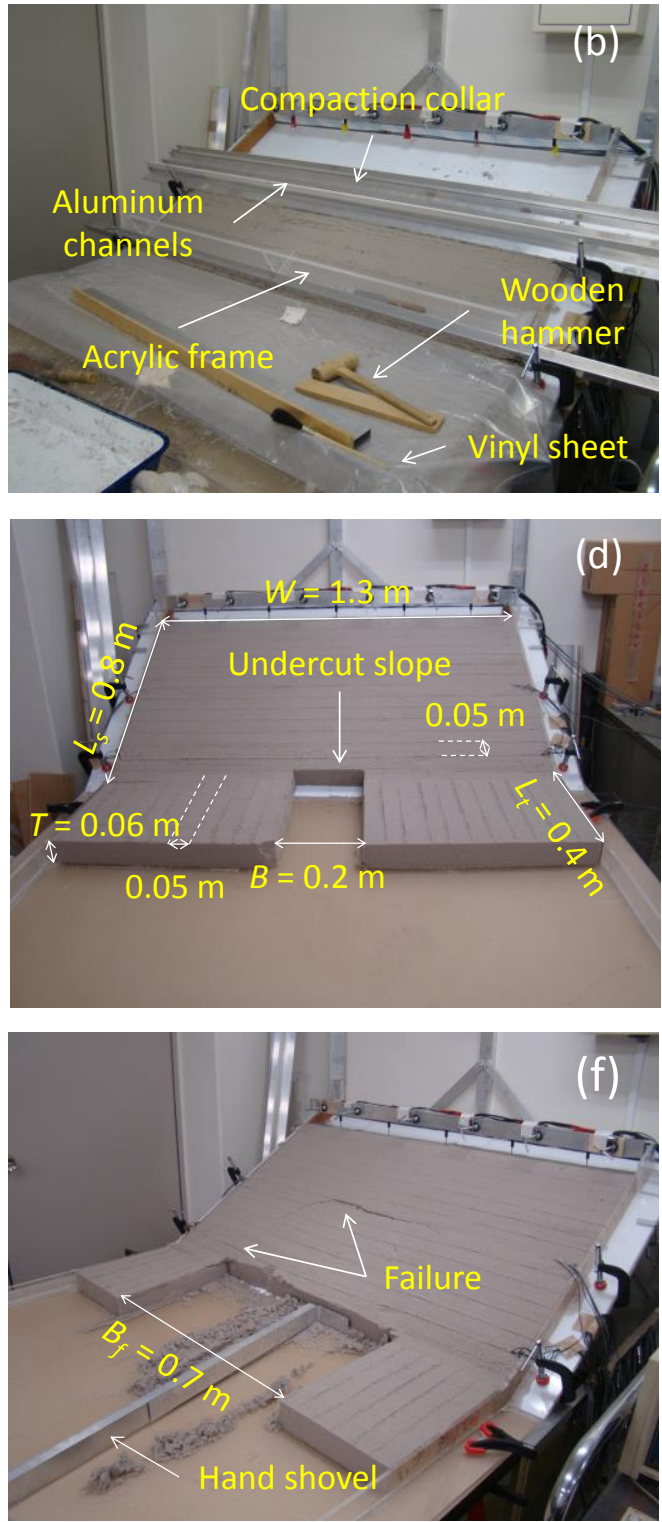

Figure 12 Typical procedure for the slope model preparation slice-by-slice and undercutting processes of the slope at the base part starting from the middle and expanding symmetrically until failure

Based on the results of the $1 \mathrm{~g}$ physical model tests, it was concluded that the downward motions of humid sand toward the inner interval of the excavation indicated that the scarp was being pushed inwardly, with upward shear stresses along two side supports. Since the humid sand was failing inwardly rather than outwardly, it can be inferred that the lateral compression would be greater than the inclined compression 
to sufficiently initiate the arch action under the passive condition. On the other hand, a load from the centre of the slope was transferred laterally to the side supports in the configuration of arch action through the trajectories of the major principal stress. These trajectories can be regarded as stacks of curved arches where the crown of the arch points upward against the cascading movement of the slope.

\subsection{Geotechnical centrifuge model}

In order to confirm the results of $1 \mathrm{~g}$ physical model tests with a higher intensity of stress, an investigation under a centrifugal acceleration of $50 \mathrm{~g}$ was performed. The in-house beam type centrifuge machine Mark III, located at the Tokyo Institute of Technology with a platform radius of $2.45 \mathrm{~m}$, was used in this study. A small-scale slope structure model was made of rigid acrylic plates, shown in Figure 13(a), and consisted of slope and toe parts. Considering the lower interface friction between Teflon and sand, compared to the internal friction of sand, a thin layer of Teflon was stuck on the slope part of the model simulating a potential failure plane. Sand paper was attached to the base part of the model increasing the frictional resistance of this part. This slope structure model was placed inside a metallic chamber with dimensions shown in Figure 13(b).
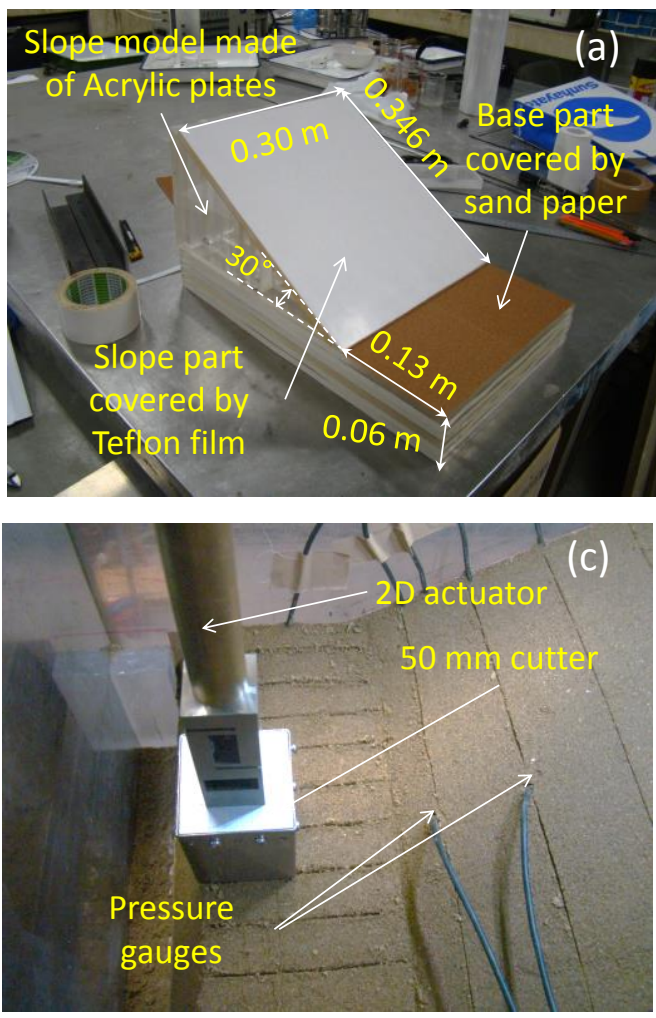
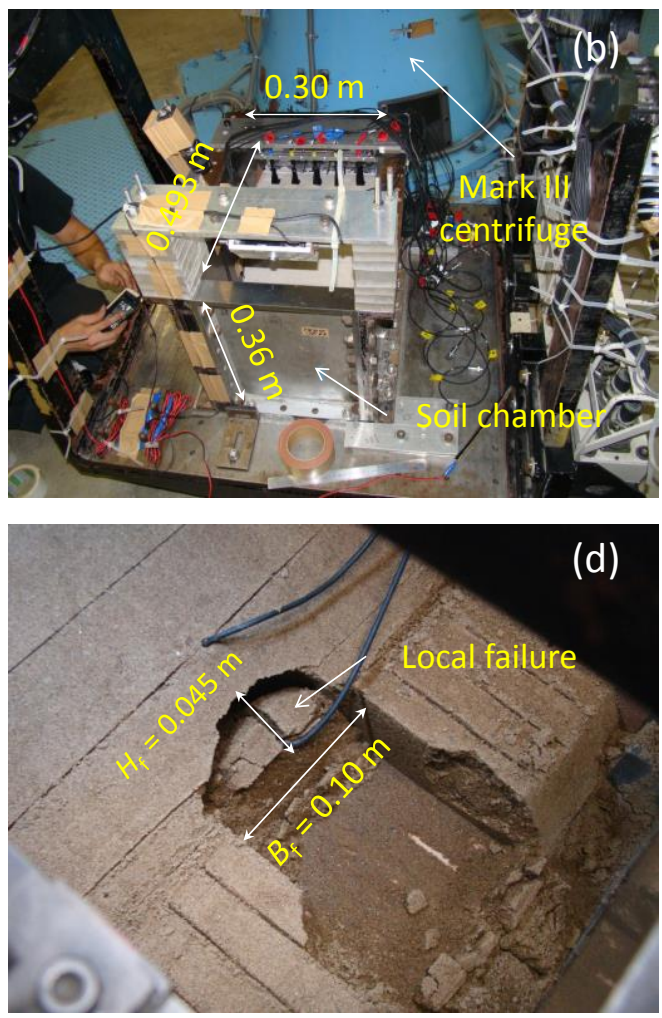

Figure 13 Slope model, soil chamber and actuator employed in the centrifuge model as well as the failure mode observed during $50 \mathrm{~g}$ in-flight excavations (after Khosravi 2012; Khosravi et al. 2016)

Despite the positive behaviour of silica sand No. 6 in the $1 \mathrm{~g}$ physical modelling, it failed to model the undercut slope under centrifugal acceleration. The reason was found to be related to the nature of this sand as a poorly graded soil. As is reported by Khosravi (2012), the loose humid silica sand No. 6 was not able to sustain its water content under centrifugal acceleration. By increasing the acceleration, the water was drained out from the soil voids leading to a decrease in the soil strength properties. Therefore, it was decided that a well-graded soil ought to be used for the centrifugal modelling. Edosaki sand, a well-graded soil with a uniformity coefficient of $C_{u}=3.1$ under an optimum water content of $15.4 \%$, was compacted in the form of a layer on both the slope and base parts of the model, as shown in Figure 13(c). The prepared model was fully instrumented with a series of pressure cells of type PS-1KC and potentiometers of type MLT-38000201 (see Khosravi et al. 2016 for details). In order to excavate into the model under a centrifugal acceleration, an in-flight excavator was installed on the model container. This in-flight excavator consisted 
of a remote controlled 2D actuator holding a cutting blade, as shown in Figure 13(c). The vertical movement of the cutting blade was controlled by a worm gear built into the stepping motors. Following the same process of excavation as was done for the $1 \mathrm{~g}$ physical model, the central toe part of the model was excavated under a constant centrifugal acceleration of $50 \mathrm{~g}$ starting with an excavating span of $50 \mathrm{~mm}$. As the excavating span was increased to $100 \mathrm{~mm}$, an arch-shaped local failure occurred on the slope part of the model, as shown in Figure 13(d).

The pressure redistribution inside the slope model was monitored by means of embedded pressure cells. The phenomenon of passive arch action was confirmed above the excavated area where the earth pressure on the central part of the slope model was reduced by increasing the excavated area while the earth pressure on both sides of the slope model was increased. Furthermore, at the central part of the slope model above the excavated area, an active to passive stress switch process was monitored. These observations were found to agree reasonably well with the results of the $1 \mathrm{~g}$ physical model tests, as previously explained.

\section{$2.4 \quad$ Numerical model}

Leelasukseree et al. (2012) conducted a numerical model using 3DEC ${ }^{\circledR}$, a 3D numerical program based on the distinct element method. Figure 14 confirms that stacks of arches acting along the major compressive stresses dominate the pattern of load transmission in the undercut slope.
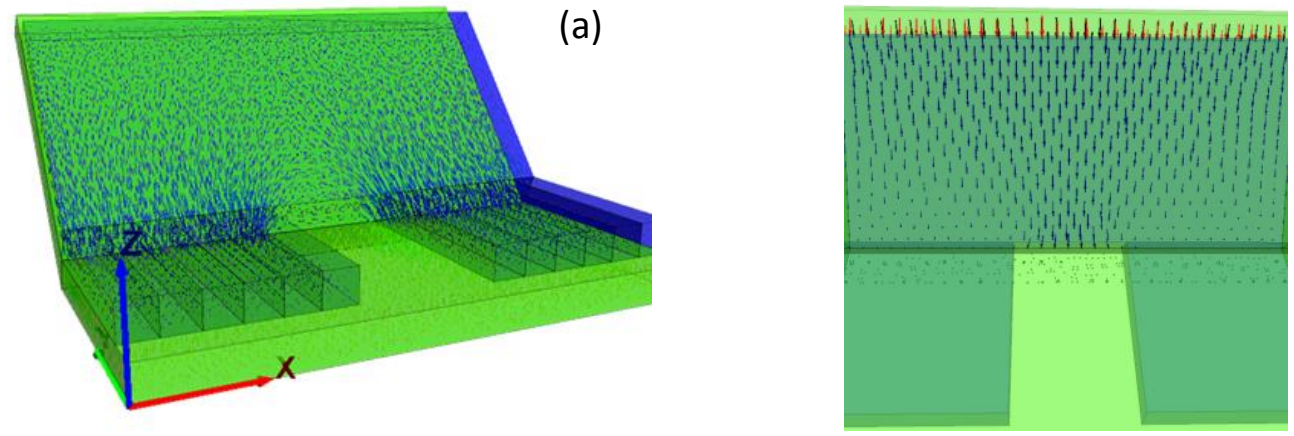

(b)

Figure 14 (a) Trajectories of major principal stress; and, (b) displacement vector distributions (modified from Leelasukseree et al. 2012)

\section{$3 \quad$ Field test}

Weathering can substantially reduce the strength of grey claystone exposed to the surface environment. In order to estimate the unconfined compressive strength of weathered grey claystone, a $1.1 \mathrm{MN}$ hydraulic jack ( $v$ Tuyl Technics BV /-/04.070.b1/10042) with a piston area of $196 \mathrm{~cm}^{2}$ was employed in the field. Five locations were chosen with a relatively flat surface in Area 4.1 where holes, $0.40 \mathrm{~m}$ wide, $0.60 \mathrm{~m}$ long and $0.35 \mathrm{~m}$ deep below the weathered surface, were dig by hand tools to provide sufficient space for the jack installation. As grey claystone would have inherent anisotropy, the holes were oriented in various directions. Two steel plates, $0.315 \times 0.350 \times 0.01 \mathrm{~m}$, that were thick enough to allow for uniform pressure acting against the applied jack force, were fitted onto both ends, as shown in Figure 15(a). To avoid errors and to reduce the variation in measurements due to premature failure, the plates were adjusted to fit flush against the surface of the holes by filling some crushed rocks into the gaps. The jack pressure was gradually increased until the steel plates laterally pushed the ground to failure when the load could not be increased anymore. The failed mass exhibited surface upheaval at some distance on one side, as shown in Figure 15(b). The detailed dimensions are illustrated in Figure 15(c). The maximum jack pressure reading was recorded and used to calculate the applied plate pressure $=$ jack pressure $\times$ piston area/plate area. The maximum plate pressure merely represents the semi-unconfined compressive strength of grey claystone in the field because three boundaries are initially confined. Nevertheless, these field tests were the only available data on hand at that time; its average would relatively represent the unconfined compressive strength of the site despite imperfect testing conditions. Table 1 summarises the results of five field tests 
conducted from 2011-2012. The recorded maximum pressures were varied with the testing locations and orientations; therefore, the grey claystone surface would retain some degree of anisotropy with a wide variation in strength due to geological and weathering factors. According to Table 1 , the average maximum pressure applied by the steel plate to fail the grey claystone is approximately $\sigma_{\mathrm{c}}=0.75 \mathrm{MPa}$, which is significantly less than the mean unconfined compressive strength 4.27 MPa reported in EGAT (1985) for grey claystone. Still, this value lies in the range between the peak value of $4.50 \mathrm{MPa}\left(\phi=45^{\circ}, c=932 \mathrm{kPa}\right)$ and the residual value of $0.33 \mathrm{MPa}\left(\phi=43^{\circ}, c=71 \mathrm{kPa}\right)$ reported by Khosravi et al. (2011b), using a rock direct shear apparatus on five core samples of grey claystone collected from Area 4.1.
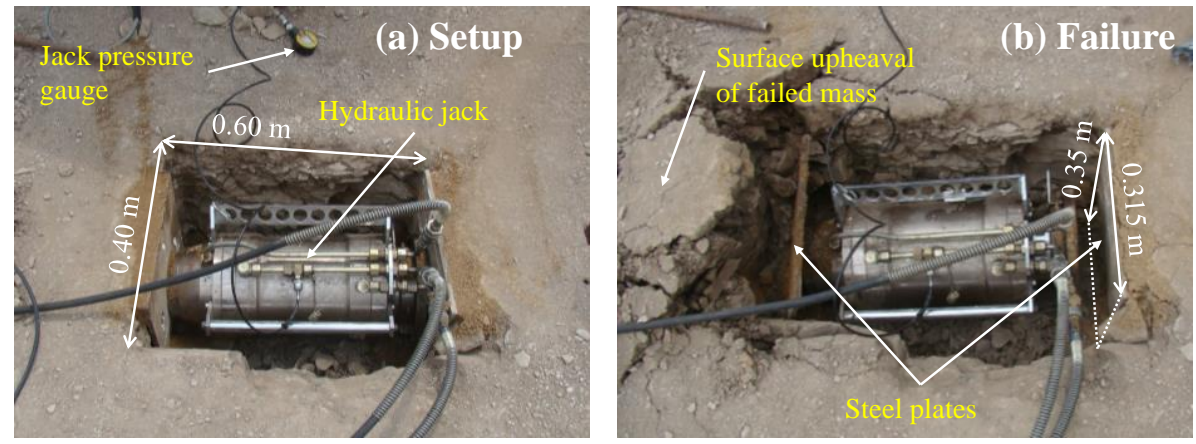

Steel plates $0.315 \times 0.350 \times 0.01 \mathrm{~m}$

(c)

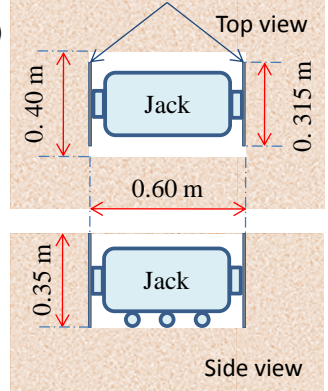

Figure 15 (a) Setup of hydraulic jack in a hole $0.40 \times 0.60 \times 0.35 \mathrm{~m}$ where both ends were attached to steel plates $0.315 \times 0.350 \times 0.01 \mathrm{~m}$; (b) failure of claystone exhibiting surface upheaval of the failed mass at one end for Test 4 conducted on 5 June 2012; and, (c) installation diagram

Table 1 Summary of field tests for compressive strength of grey claystone by using a hydraulic jack

\begin{tabular}{cccc}
\hline Test № & Date & Maximum plate pressure (MPa) & Location \\
\hline Test 1 & $2011 / 9 / 27$ & 0.27 & - \\
\hline Test 2 & $2012 / 5 / 17$ & 1.60 & $\mathrm{~N} 18^{\circ} 19.923^{\prime}, \mathrm{E}^{\circ} 9^{\circ} 44.185^{\prime}$ \\
\hline Test 3 & $2012 / 5 / 31$ & 0.41 & $\mathrm{~N} 18^{\circ} 19.934^{\prime}$, E99 $44.183^{\prime}$ \\
\hline Test 4 & $2012 / 6 / 05$ & 0.87 & $\mathrm{~N} 18^{\circ} 19.211^{\prime}$, E99 $41.748^{\prime}$ \\
\hline Test 5 & $2012 / 6 / 06$ & 0.60 & - \\
\hline Average & & 0.75 & \\
\hline
\end{tabular}

In the field tests, the average water content $w=17.8 \%$ and the surface temperature of $37.6^{\circ} \mathrm{C}$ were measured using the sensor probe (ARP WD-3-WET-5E). The total unit weight of the grey claystone samples was $\gamma_{t}=19.40 \mathrm{kN} / \mathrm{m}^{3}$, obtained by the weight measurement and the volume displacement method in the laboratory. These values are close to the mean total unit weight of $19.12 \mathrm{kN} / \mathrm{m}^{3}$ and the mean water content of $21.5 \%$ reported in EGAT (1985). Adopting the specific gravity of particles of grey claystone $G_{\mathrm{s}}=2.68$ based on EGAT (1985), the dry unit weight $\gamma_{d}=16.47 \mathrm{kN} / \mathrm{m}^{3}$, the void ratio $e=0.6$ and the saturated unit weight $\gamma_{\text {sat }}=20.13 \mathrm{kN} / \mathrm{m}^{3}$ can be calculated by Equations (1)-(3), (Lambe \& Whitman 1969, p.30) using the unit weight of water $\gamma_{w}=9.81 \mathrm{kN} / \mathrm{m}^{3}$.

$$
\begin{gathered}
\gamma_{s a t}=\frac{G_{s}+e}{1+e} \gamma_{w} \\
e=\frac{G_{s} \gamma_{w}}{\gamma_{d}}-1 \\
\gamma_{t}=(1+w) \gamma_{d}
\end{gathered}
$$


where:

$$
\begin{aligned}
& G_{s}=\text { specific gravity of solid particles. } \\
& e=\text { void ratio of rock mass. } \\
& w=\text { water content of rock mass. } \\
& \gamma_{s a t}=\text { saturated unit weight of rock mass. } \\
& \gamma_{t}=\text { total unit weight of rock mass. } \\
& \gamma_{d}=\text { dry unit weight of rock mass. }
\end{aligned}
$$

\section{$4 \quad$ Undercut width of slope}

Soil arching above the opening has been studied in hoppers (Jenike 1961; Walker 1966), tunnels (Terzaghi 1936; Wong \& Kaiser 1991), trenches (Tsai \& Chang 1996; Wong 1984), stabilising piles (Bosscher \& Gray 1986; Wang \& Yen 1974), pile-supported embankments (Hong et al. 2007; Low et al. 1994) and slopes (Guo \& Zhou 2013). In a problem limiting an undercut slope lying on a bedding plane, a practical technique for surface mining was established at the Mae Moh mine under collaborative research with the Electricity Generating Authority of Thailand (EGAT), successfully resulting in a fundamental study on the failure mechanism of undercut slopes (Khosravi 2012; Pipatpongsa et al. 2012). Pipatpongsa et al. (2013) proposed the following equation to describe the failed undercut width based on Jenike (1961):

$$
B_{f}=\frac{k}{\left(\sin \alpha-\tan \phi_{i} \cos \alpha\right)-\left(c_{i} / \gamma T\right)} \frac{\sigma_{c}}{\gamma}
$$

where:

$$
\begin{aligned}
& B_{f}=\text { failure undercut width. } \\
& \alpha=\text { inclined angle of the slope. } \\
& T=\text { thickness of the slope above the bedding plane. } \\
& \phi_{i}=\text { interface friction angle of the filled material in the bedding plane. } \\
& c_{i}=\text { interface adhesion of the filled material in the bedding plane. } \\
& \sigma_{c}=\text { unconfined compressive strength of the rock slope. } \\
& \gamma \quad=\text { unit weight of the rock mass. } \\
& \phi \quad=\text { angle of shearing resistance of the rock mass. } \\
& k=\text { arching coefficients are defined as follows: } \\
& \quad 0: \text { no arching, } \cos (\phi): \text { strip arch, } 1: \text { segmented arch, } 4 / \pi \text { : circular arch. }
\end{aligned}
$$

Pipatpongsa et al. (2013) considered the failure undercut width under fully saturated condition and full seepage conditions to which Equation (4) is modified:

$$
B_{f}=\frac{\sigma_{c}}{\left(\gamma+\gamma_{w}\right) \sin \alpha-\left(\gamma-\gamma_{w}\right) \tan \phi_{i} \cos \alpha}
$$

In this study, Equation (5) is revised to Equation (6) by replacing a term $\left(\gamma+\gamma_{w}\right)$ with $\gamma_{\text {sat }}$, and a term $\left(\gamma-\gamma_{w}\right)$ with $\left(\gamma_{s a t}-\gamma_{w}\right)$. After rearrangement, the fully saturated conditions are correctly satisfied:

$$
B_{f}=\frac{1}{\sin \alpha-\left(1-\gamma_{w} / \gamma_{s a t}\right) \tan \phi_{i} \cos \alpha} \frac{\sigma_{c}}{\gamma_{s a t}}
$$


As a result, the corrected failure width of the undercut slope in Area 4.1 is $181 \mathrm{~m}$, not $142 \mathrm{~m}$, as was reported in Pipatpongsa et al. (2013) using the parameters shown in Table 2 (Pipatpongsa et al. 2011, 2013).

Table 2 Designed parameters for the geometry, laboratory and field tests

\begin{tabular}{cc} 
Parameters & Designed values \\
\hline Inclined angle of the bedding plane, $\alpha$ & $18^{\circ}$ \\
\hline Thickness of slope above the bedding plane, $T$ & $33 \mathrm{~m}$ \\
\hline Angle of shearing resistance of clay seam, $\phi_{i}$ & $12^{\circ}$ \\
\hline Unconfined compressive strength of grey claystone, $\sigma_{c}$ & $0.75 \mathrm{MPa}$ \\
\hline Saturated unit weight of grey claystone, $\gamma_{\text {sat }}$ & $20.13 \mathrm{kN} / \mathrm{m}^{3}$ \\
\hline Unit weight of water, $\gamma_{w}$ & $9.81 \mathrm{kN} / \mathrm{m}^{3}$ \\
\hline
\end{tabular}

Pipatpongsa et al. (2013) reported the exposed undercut width of $130 \mathrm{~m}$ as of October 2012, excavating from the elevation of $192 \mathrm{~m}$ above the level of the clay seam to the elevation of $159 \mathrm{~m}$ below the level of the clay seam, when this design concept was applied to Area 4.1 with a Factor of Safety of 1.1. According to the corrected formula of $B_{f}$ and the revised values of $\sigma_{c}$ and $\gamma_{s a t}$, based on field tests, the corrected Factor of Safety should be $181 \mathrm{~m} / 130 \mathrm{~m}=1.4$ for that time, when the outcrops of clay seams $\mathrm{G} 1$ and G1A had been daylighted.

The undercut slope in Area 4.1 has held up over four rainy seasons, while the slope on the right side of the excavated pit was dumped with overburden claystone. According to the mining plan, lignite in front of Area 4.1 was mined until reaching an elevation of $115 \mathrm{~m}$. Hence, the undercut slope was deepened into the pit by seven $11 \mathrm{~m}$ high benches with no serious failure. Figure 16 shows a panoramic view of Area 4.1 as of September 2015, confirming the practical achievement of the design concept of undercut slopes in surface mining.
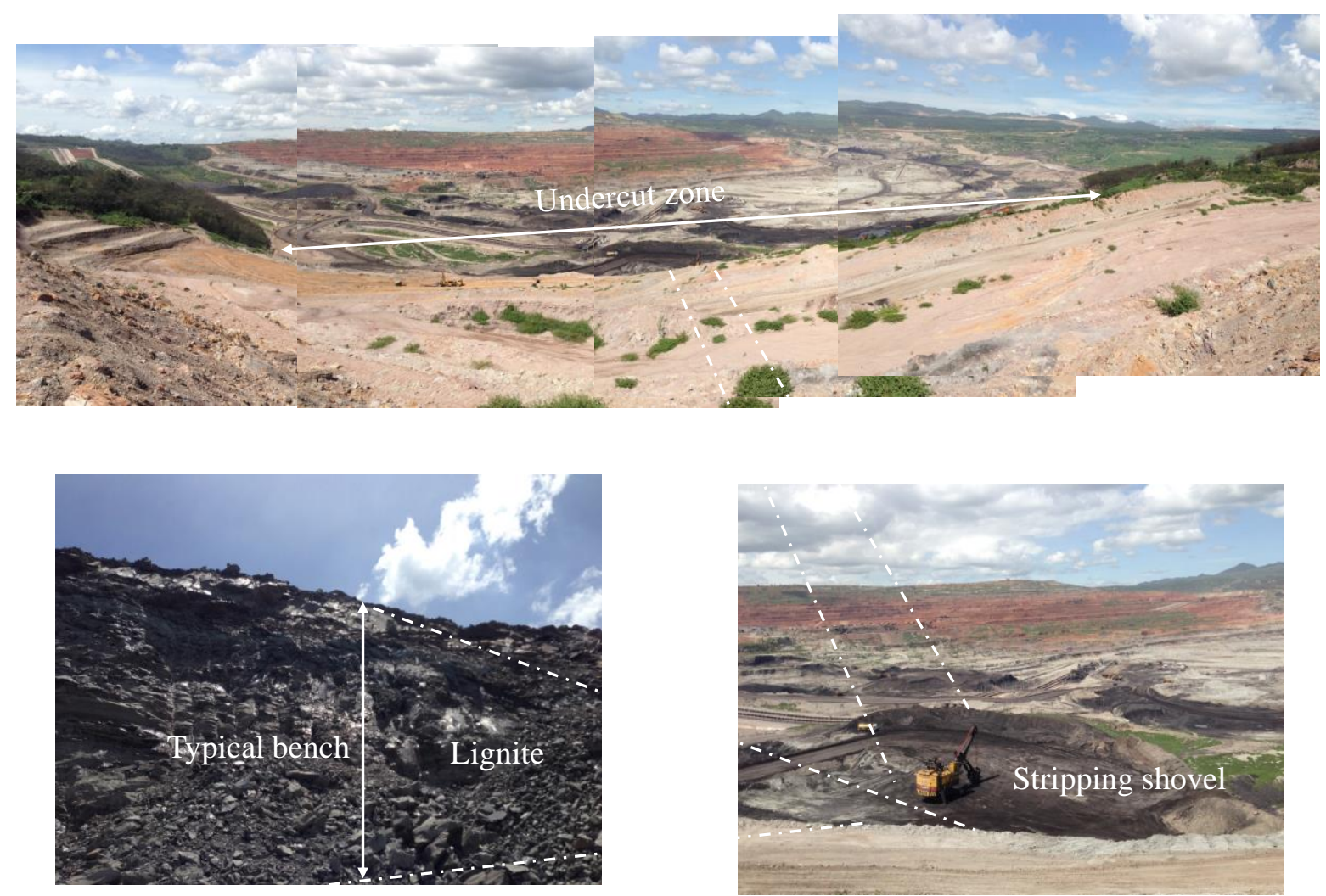

Figure 16 Panoramic view of Area 4.1 looking from the top of the slope, showing the actual stage of excavation at 9 September 2015 


\section{Conclusion}

The engineering challenge in Area 4.1 of the Mae Moh lignite open pit mine was reviewed together with the concepts of the excavation method based on the arching effect and the cut-and-fill technique. Through the present study, the arch action and its mechanism of load transfer were confirmed by means of a number of physical and numerical models while briefly providing technical information on the modelling concept.

It was concluded that the failure mechanism, along the inclined plane of the weak plane, involves the passive condition where the major principal stresses dominate the force supporting the arches in the circumferential direction and the minor principal stresses represent the force confining the stacks of arches. The newly developed design concept, based on the authors' studies, was introduced as an applicable method for surface mining in open-pit mines with a satisfactory performance.

The design concept for undercut slopes, used in the previous study (Pipatpongsa et al. 2013), was revised in this study. The efforts contributing to this research, conducted from 2010-2015, confirm that the undercut slope procedure is practically realisable and results in a reduction in the massive excavation, transportation and dumping of unstable rock masses, as well as in the saving of mining-related time and expenses.

\section{Acknowledgement}

This study is part of two research projects, namely, "Failure Mechanisms and Stabilisation of Undercut Slope with Faults at Lowwall Area 4.1 by Using Shear Pins and Rock Bunds" and "Stabilisation of Alternative Excavations and Strengthening of Supporting Materials for Pit Wall in Area 4.1" funded by EGAT. The partial financial support provided by MEXT/JSPS KAKENHI grant numbers 23760441, 25820213 and 15H04037, the JSPS Asian CORE Program, and the Global COE (Centres of Excellence) Program, Centre for Urban Earthquake Engineering at Tokyo Institute of Technology is truly appreciated.

Sincere thanks are also given to Mr Sakae Seki, Mr Soksan Thay, Mr Lin Tang, Mr Shuhei Kitakata, Mr Hidehira Hirai, Mr Thanachote Techawongsakorn, Mr Rithy Ouch, Mr Cyril Borely and Mr Dionysios Stathas for their valuable assistance with the laboratory testing as well as to the entire staff of the Geotechnical Engineering Department, Slope Stability Monitoring Section of EGAT for their helpful information on the Mae Mon mine. Appreciation is also extended to Mr Narongsak Mavong, Mr Apipat Chaiwan, Dr Pitiwat Wattanachai and Dr Barames Vardhanabhuti for the useful series of discussions shared with them.

\section{References}

Bosscher, PJ \& Gray, DH 1986, 'Soil arching in sandy slopes', Journal of Geotechnical Engineering-ASCE, vol. 112, no. 6, pp. 626-645. EGAT (Electricity Generating Authority of Thailand) 1985, Thailand-Australia Lignite Mines Development Project, Geotechnical Report, Mae Moh Mine, vol. 3.

Guo, P \& Zhou, S 2013, 'Arch in granular materials as a free surface problem', International Journal for Numerical and Analytical Methods in Geomechanics, vol. 37, no. 9, pp. 1048-1065.

Hoek, E \& Bray, J 1977, Rock Slope Engineering, The Institution of Mining and Metallurgy, London.

Hong, WP, Lee, JH \& Lee, KW 2007, 'Load transfer by soil arching in pile-supported embankments', Soils and Foundations, vol. 47, no. 5, pp. 833-843.

Jenike, AW 1961, 'Gravity flow of bulk solid', Bulletin of the Utah Engineering Experiment Station, vol. 52, no. 29, pp. 1-309.

Khosravi, MH 2012, 'Arching effect in geomaterials with applications to retaining walls and undercut slopes', Doctoral thesis, Tokyo Institute of Technology.

Khosravi, MH, Pipatpongsa, T, Leelasukseree, C \& Wattanachai, P 2009, 'Failure mechanisms in arched excavation of sloped earth using model test', in Proceedings of Geo-Kanto 2009, Japanese Geotechnical Society, Tochigi, pp. 241-246.

Khosravi, MH, Carlton, OJ, Pipatpongsa, T, Takemura, J \& Doncommul, P 2010, 'A preliminary study of moving-pit excavation for environmental load reduction in open-cast mining', in Proceedings UP ICE Centennial Conference on Harmonizing Infrastructure with the Environment featuring the 3rd ASEAN Civil Engineering Conference and the 3rd ASEAN Environmental Engineering Conference, University of the Philippines Diliman, p. GEO_11.

Khosravi, MH, Pipatpongsa, T, Takahashi, A \& Takemura, J 2011a, 'Arch action over an excavated pit in a stable scarp investigated by physical model tests', Soils and Foundations, vol. 51(4), pp. 723-735. 
Khosravi, MH, Pipatpongsa, T, Takemura, J, Mavong, N \& Doncommul, P 2011b, 'Investigation on shear strength of shale at the Mae Moh open-pit mine', in Proceedings of the 4th Thailand-Japan International Academic Conference, Thai Students' Association in Japan under the Royal Patronage, The University of Tokyo, pp. 51-52.

Khosravi, MH, Tang, L, Pipatpongsa, T, Takemura, J \& Doncommul, P 2012, 'Performance of counterweight balance on stability of undercut slope evaluated by physical modeling', International Journal of Geotechnical Engineering, vol. 6(2), pp. 193-205.

Khosravi, MH, Pipatpongsa, T \& Takemura, J 2013, 'Interface shearing resistance properties between moist silica sand and surface of materials investigated by direct shear apparatus', Geo-Kanto2013, Japanese Geotechnical Society, Miraikan, Tokyo, pp. MAT 4-5.

Khosravi, M, Takemura, J, Pipatpongsa, T \& Amini, M 2016, 'In-flight excavation of slopes with potential failure planes', Journal of Geotechnical and Geoenvironmental Engineering, vol. 142, no. 5, pp. 06016001.

Lambe, TW \& Whitman, RV 1969, Soil Mechanics, John Wiley \& Sons, Inc.

Leelasukseree, C, Pipatpongsa, T, Khosravi, MH \& Mavong, N 2012, 'Stresses and a failure mode from physical and numerical models of undercut slope lying on inclined bedding plane', in Proceedings of 7th Asian Rock Mechanics Symposium, Seoul, pp. 1295-1304.

Low, BK, Tang, SK \& Choa, V 1994, 'Arching in piled embankments', Journal of Geotechnical Engineering, vol. 120(11), pp. $1917-1938$.

Pipatpongsa, T, Heng, S, Likitlersuang, S, Mungpayabal, N \& Ohta, H 2011, 'Investigation of mechanical properties of clay seam in bedding shears of the Mae Moh open-pit mine of Thailand', in M Shahin \& H Nikraz (eds), Proceedings of the International Conference on Advances in Geotechnical Engineering, Perth, pp. 209-214.

Pipatpongsa, T, Khosravi, MH, Doncommul, P \& Mavong, N 2009, 'Excavation problems in Mae Moh lignite open-pit mine of Thailand', in Proceedings of Geo-Kanto 2009, Tochigi, pp. 459-464.

Pipatpongsa, T, Khosravi, MH, Leelasukseree, C, Mavong, N \& Takemura, J 2010, 'Slope failures along oblique plane due to sequential removals of propping portion in physical model tests', in 15th National Convention on Civil Engineering, Engineering Institute of Thailand, Ubon Ratchathani University, vol. GTE60, p. 135.

Pipatpongsa, T, Khosravi, MH, Takemura, J, Stathas, D \& Leelasukseree, C 2012, 'Cohesive arch action in laterally confined block of moist sand placing on an inclined bedding plane', in Proceedings of 7th Asian Rock Mechanics Symposium, Korean Society for Rock Mechanics, Seoul, pp. 1378-1387.

Pipatpongsa, T, Khosravi, MH \& Takemura, J 2013, 'Physical modeling of arch action in undercut slopes with actual engineering practice to Mae Moh open-pit mine of Thailand', in 18th International Conference on Soil Mechanics and Geotechnical Engineering, The French Society for Soil Mechanics and Geotechnical Engineering, Paris, vol. 2, pp. 943-946.

Terzaghi, K 1936, 'Stress distribution in dry and in saturated sand above a yielding trap-door', in First International Conference on Soil Mechanics and Foundation Engineering, Harvard University, Cambridge, vol. 1, pp. 307-311.

Tsai, JS \& Chang, JC 1996, 'Three-dimensional stability analysis for slurry-filled trench wall in cohesionless soil', Canadian Geotechnical Journal, vol. 33, no. 5, pp. 798-808.

Walker, DM 1966, 'An approximate theory for pressures and arching in hoppers', Chemical Engineering Science, vol. 21, no. 11, pp. 975-997.

Wang, WL \& Yen, BC 1974, 'Soil arching in slopes', Journal of the Geotechnical Engineering Division - ASCE, vol. 100, no. GT1, pp. 61-78.

White, DJ, Take, WA \& Bolton, MD 2003, 'Soil deformation measurement using particle image velocimetry (PIV) and photogrammetry', Geotechnique, vol. 53, no. 7, pp. 619-631.

Wong, GCY 1984, 'Stability analysis of slurry trenches', Journal of Geotechnical Engineering, vol. 110, no. 11, pp. 1577-1590.

Wong, RCK \& Kaiser, PK 1991, 'Performance assessment of tunnels in cohesionless soils', Journal of Geotechnical Engineering-ASCE, vol. 117, no. 12, pp. 1880-1901.

Wyllie, DC \& Mah, C 2004, Rock Slope Engineering, CRC Press. 